http://jmscr.igmpublication.org/home/

ISSN (e)-2347-176x ISSN (p) 2455-0450

crossref DOI: https://dx.doi.org/10.18535/jmscr/v7i11.176

Journal Of Medical Science And Clinical Research

IGM Publication

An official Publication of IGM Publication

\title{
Management and outcomes of the patients admitted in SNCU
}

\author{
Authors \\ Ankur Dharmani MD', Sonia Kashyap MD ${ }^{2 *}$ \\ ${ }^{1}$ Pediatrician, Regional Hospital, Bilaspur H.P \\ ${ }^{2 *}$ Internal Medicine (Medical Specialist), DDU, Shimla, HP \\ *Corresponding Author \\ Sonia Kashyap MD
}

\begin{abstract}
Introduction: The proliferation of secondary and tertiary level neonatal intensive care units (NICUs) has led to dramatic improvement in median survival rates of $58 \%$ and $88 \%$ among extremely low birth weight $(L B W)$ and very $L B W$ newborns, respectively.

Materials and Method: It was an observational study done at Regional hospital Bilaspur catering rural area population of Bilaspur, study includes both inborn and out born babies admitted in SNCU between 2015 to 2018.

Results: Most of the patient got discharge 1456 (87.8\%), 40 (2.4\%) out of total admission of newbourns died. Most of the neonatal death was recorded within 1 day and between the periods of 1 - 3 days of admission 0.8\%. 0.98\% of new bourns died with 1 to 6 days of age.

Conclusion: Improve neonatal outcome, it is imperative to be vigilant especially during the first 24 hours of life.

Keywords: Special neonatal care unit.
\end{abstract}

\section{Introduction}

Newborn health is now considered as high level national priority globally ${ }^{[1]}$. The current neonatal, infant, and under five mortality rate in India are 24,32 , and 34/1000 live births, respectively ${ }^{[2]}$. Thus, neonatal mortality constitutes the major proportion of under five mortality in India as well as other countries ${ }^{[2]}$. After the introduction of the National Rural Health Mission (NRHM), especially Janani Suraksha Yojana in 2005 for improvement in maternal and child health, there has seen a tremendous growth of neonatal intensive care in India $^{[2]}$. The proliferation of secondary- and tertiary level neonatal intensive care units (NICUs) has led to dramatic improvement in median survival rates of $58 \%$ and $88 \%$ among extremely low birth weight (LBW) and very LBW newborns, respectively ${ }^{[3]}$.

The India Newborn Action Plan launched in September 2014, for accelerating the reduction of preventable newborn deaths and stillbirths in the country has a goal of attaining "Single Digit Neonatal Mortality Rate (NMR) by 2030", ${ }^{[1]}$. The National Neonatology Forum of India stratifies neonatal care into three levels as follows: Level I includes basic resuscitation and healthy newborn care, Level II includes care of preterm newborn $>32$ weeks gestational age (GA) (subdivided into IIA and IIB based on brief ventilation of $<24 \mathrm{~h}$ and continuous positive airway pressure (CPAP) 
support), and Level III includes care of extreme preterm newborns ${ }^{[4]}$. Under the NRHM, sick neonatal care units (SNCUs) are established as secondary level NICUs, generally at district level hospitals. Ideally, these should possess 1220-bedded units, with 4 trained doctors, and 1012 nurses and support staff with the provision of $24 \times 7$ services to sick newborns, except assisted ventilation, and major surgeries ${ }^{[4]}$. Neonates who require higher intensive care are referred to tertiary level NICUs at apex centers ${ }^{[4]}$. In a country like India, where the majority of neonatal care occurs in secondary level NICUs, it is a priority for health-care officials to divert the resources for improvising these SNCUs to bring down the $\mathrm{NMR}^{[4]}$. Hence, it is high time, a clinical study should be performed in a secondary care NICU to reveal the true picture of neonatal management and outcome in SNCU.

\section{Materials and Method}

It was an observational study done at Regional hospital Bilaspur catering rural area population of Bilaspur, surrounding areas of Mandi, Hamirpur and Solan districts, Study includes both inborn and out born babies admitted in SNCU between 2015 to 2018.

This SNCU has 8 beds, It is equipped with phototherapy unit, radiant warmer, oxygen concentrator, suction machine, generator/inverter. The admission criteria of this SNCU allows admitting newborns with birth weight $<2500 \mathrm{~g}$, GA <37 weeks, multiple deliveries (twins and triplets), major life threatening malformations, birth asphyxia requiring endotracheal intubation and/or requiring bag and mask ventilation for at least $5 \mathrm{~min}$, meconium aspiration syndrome, respiratory distress syndrome (RDS), transient tachypnea of newborn and other newborns with respiratory distress since birth and newborns with central cyanosis (not improving with oxygen therapy). Other important clinical indications include neonatal seizures, significant birth injury, history of prolonged rupture of membrane in mother $>24 \mathrm{~h}$ due to increased risk of early-onset neonatal sepsis (EONS), if the mother is sick and unable to provide adequate care to the newborn, babies born to diabetic mother, especially if the mother is a poorly controlled diabetic and the baby is macrosomic, babies born to mother with $\mathrm{Rh}$ isoimmunization in pregnancy, babies with neonatal hyperbilirubinemia requiring phototherapy and babies with hypoglycemia, polycythemia, lethargy, or neonatal sepsis. Ethical clearance from pediatric department of concerned hospital.

\section{Results}

Total 1 indicates that 1658 newborns were admitted in SNCU, $37.2 \%$ newbourns were having weight less than $2500 \mathrm{gm}$. Total male babies were 977 (58.9\%) and female babies were $672(40.5 \%)$. Out of total $1254(75.6 \%)$ were inbourn and $453(24.3 \%)$ were out born. 519 $(31.3 \%)$ new bourns were pre term and 1142 $(68.8 \%)$ were term babies. Significantly higher number of inborn babies were admitted compared to out born babies.

Table no. 2, 921 (55.5\%) new bourns received phototherapy, 589 (35.5\%) received antibiotic, and $401(24.1 \%)$ received oxygen. Most of the patient got discharge 1456 (87.8\%), 40 (2.4\%) out of total admission of new bourns died. 725 (43.7\%)new bourns were having hospital stay for 1-3 day, 577 (34.8\%) stayed in hospital for 4-7 days. In our hospital 1 radio warmer and 1 suction machine was non function during all the years of research.

Table no. 3, most of the neonatal death were recorded within 1 day and between the period of 1 - 3 days of admission $0.8 \% .0 .98 \%$ of new bourns died with 1 to 6 days of age. 19 preterm babies died which is $1 \%$ of all new bourns admitted in SNCU. Most of the deaths were observed in term and pre term babies. 
Table no. 1: SNCU admission record

\begin{tabular}{|c|c|c|c|c|c|}
\hline \multirow{2}{*}{\multicolumn{2}{|c|}{ Admicsion in the unit }} & 2015 & 2016 & 2017 & 2018 \\
\hline & Admission in the unit & 196 & 394 & 460 & 608 \\
\hline \multicolumn{2}{|l|}{ Male } & 117 & 235 & 271 & 354 \\
\hline \multicolumn{2}{|l|}{ Female } & 79 & 159 & 180 & 254 \\
\hline \multirow{4}{*}{$\begin{array}{l}\text { Birth weight of } \\
\text { the baby at the } \\
\text { time of } \\
\text { admission }\end{array}$} & $\geq 2500$ gm & 98 & 226 & 286 & 421 \\
\hline & $1500-2499 \mathrm{gm}$ & 82 & 154 & 149 & 163 \\
\hline & $1000-1499 \mathrm{gm}$ & 15 & 14 & 19 & 22 \\
\hline & $<1000 \mathrm{gm}$ & 1 & 1 & 7 & 3 \\
\hline \multirow[t]{3}{*}{ Gestation } & $>37$ weeks & 122 & 269 & 319 & 432 \\
\hline & 34-37 weeks & 55 & 90 & 109 & 141 \\
\hline & $<34$ weeks & 19 & 36 & 33 & 36 \\
\hline
\end{tabular}

Table no. 2 Management and outcome

\begin{tabular}{|c|c|c|c|c|c|}
\hline & & 2015 & 2016 & 2017 & 2018 \\
\hline \multirow[t]{3}{*}{ Management } & Phototherapy & 82 & 204 & 262 & 373 \\
\hline & Antibiotic & 85 & 187 & 177 & 140 \\
\hline & Oxygen & 68 & 87 & 97 & 149 \\
\hline \multirow[t]{2}{*}{ Step down care } & $\begin{array}{l}\text { No. of babies managed in the unit } \\
\text { from postnatal ward / step down }\end{array}$ & & & & \\
\hline & $\begin{array}{l}\text { No. of babies managed in the step } \\
\text { down from }\end{array}$ & 41 & 9 & 23 & 169 \\
\hline \multirow[t]{4}{*}{ Outcome } & Discharge & 150 & 345 & 407 & 554 \\
\hline & Referral & 26 & 45 & 42 & 39 \\
\hline & LAMA & 0 & 1 & 0 & 5 \\
\hline & Died & 12 & 10 & 7 & 11 \\
\hline \multirow[t]{4}{*}{ Duration of stay } & $<1$ day & 15 & 23 & 28 & 25 \\
\hline & $1-3$ days & 70 & 143 & 183 & 329 \\
\hline & 4-7 days & 47 & 144 & 195 & 191 \\
\hline & $>7$ days & 56 & 91 & 50 & 64 \\
\hline \multirow[t]{5}{*}{$\begin{array}{l}\text { No of non functional } \\
\text { equipment }\end{array}$} & Phototherapy unit & 0 & 0 & 0 & 0 \\
\hline & Radiant warmer & 1 & 1 & 1 & 1 \\
\hline & Oxygen generator & 0 & 0 & 0 & 0 \\
\hline & Suction machine & 1 & 1 & 1 & 1 \\
\hline & Generator/ invertor & 0 & 0 & 0 & 0 \\
\hline
\end{tabular}

Table no. 3 Death record of SNCU

\begin{tabular}{|l|c|c|c|c|c|}
\hline \multicolumn{2}{|c|}{} & $\mathbf{2 0 1 5}$ & $\mathbf{2 0 1 6}$ & $\mathbf{2 0 1 7}$ & $\mathbf{2 0 1 8}$ \\
\hline \multirow{3}{*}{$\begin{array}{l}\text { Duration between the time of } \\
\text { admission }\end{array}$} & $<1$ day & 5 & 3 & 3 & 4 \\
\cline { 2 - 6 } & $1-3$ days & 3 & 3 & 3 & 6 \\
\cline { 2 - 6 } & $4-7$ days & 3 & 2 & 1 & 0 \\
\cline { 2 - 6 } & $>7$ days & 1 & 2 & 0 & 1 \\
\hline \multirow{4}{*}{ Age at death } & $<1$ day & 5 & 2 & 1 & 4 \\
\cline { 2 - 6 } & $1-6$ days & 5 & 4 & 5 & 4 \\
\cline { 2 - 6 } & $\geq 7$ days & 2 & 4 & 1 & 3 \\
\hline \multirow{5}{*}{ Birth weight } & $\geq 2500$ gm & 5 & 3 & 1 & 7 \\
\cline { 2 - 6 } & $1500-2499$ gm & 3 & 6 & 2 & 2 \\
\cline { 2 - 6 } & $1000-1499$ gm & 4 & 1 & 0 & 1 \\
\cline { 2 - 6 } & $<1000$ gm & 0 & 0 & 4 & 1 \\
\hline Gestation & Term & 5 & 5 & 2 & 7 \\
\cline { 2 - 6 } & Preterm & 5 & 5 & 5 & 4 \\
\cline { 2 - 6 } & Post term & 2 & 0 & 0 & 0 \\
\hline
\end{tabular}

\section{Discussion}

In our study most of the patient got discharge $(88.4 \%)$. Prinja et al. described four secondary level NICUs (Vaishali, Guna, Bhubaneswar, Shivpuri) in three different states of India in $2013^{[5]}$. All four NICUs had a discharge rate 
between $60 \%$ and $80 \%$, comparable to our clinical study. Yousuf et al. reported $85 \%$ successful discharge out of 336 neonates from a secondary level of NICU in Bathinda, Punjab, in $2017^{[6]}$.

Patil Ravindra et al., in 2014, in a cross sectional study in tertiary care NICU in Shivamogga, Karnataka described around $82 \%$ discharge rate and $10 \%$ mortality rate among 1041 neonates $^{[7]}$

Rakholia et al. and other rural India studies ${ }^{[8-11]}$. During the study, the out born admissions were less in number compared to inborn admissions. The low out born admission directs the need to strengthen referral system with community based interventions.

This study found lower rate of neonatal mortality $2.1 \%$ compared to other studies conducted in India. Out of total 40 deaths, $30(75 \%)$ died within first 72 hours of admission (71.2\%), and 30\% occurring in the first 24 hours. Such early deaths in SCBU have also been reported by several other workers in the developing countries, and all points toward revisiting circumstances during labour and delivery, timely referral, and timely seeking of medical assistance by parents. With the exception of SBA and congenital malformation, neonatal mortality rates were invariable higher among the LBW infants in all the neonatal problems considered. It became obvious that any reduction in the overall neonatal mortality will aim at instituting measures that will reduce the incidence of LBW deliveries.

\section{Conclusion}

Majority of the admissions occurred within the first 24 hours of life. Therefore to improve neonatal outcome, it is imperative to be vigilant especially during the first 24 hours of life. Progress is possible, but only if we manage to prevent or detect and treat problems as early as possible, which can be achieved by public awareness, training of manpower and procurement of necessary equipment's.

\section{References}

1. Sankar MJ, Neogi SB, Sharma J, Chauhan M, Srivastava R, Prabhakar PK, et al. State of newborn health in India. $J$. Perinatol.2016;36(s3):S3-8.

2. Godinho M, Murthy S, Lakiang T, Puranik A, Nair S. Mapping neonatal mortality in India: A closer look. Indian J Community Med [Internet] 2017 [cited 2019 Nov 26];42(4):234. Available from: http://www.ijcm.org.in/text.asp?2017/42/4 /234/217233

3. Bora JK, Saikia N. Neonatal and underfive mortality rate in Indian districts with reference to Sustainable Development Goal 3: An analysis of the National Family Health Survey of India (NFHS), 20152016. PLoS One [Internet] 2018 [cited 2019 Nov 26];13(7):e0201125. Available from:

https://dx.plos.org/10.1371/journal.pone.0 201125

4. Wang $\mathrm{H}$, Abajobir AA, Abate $\mathrm{KH}$, Abbafati C, Abbas KM, Abd-Allah F, et al. Global, regional, and national under-5 mortality, adult mortality, age-specific mortality, and life expectancy, 1970-2016: A systematic analysis for the Global Burden of Disease Study 2016. Lancet 2017;390(10100):1084-150.

5. Prinja S, Manchanda N, Mohan P, Gupta G, Sethy G, Sen A, et al. Cost of neonatal intensive care delivered through district level public Hospitals in India. Indian Pediatr 2013;50(9):839-46.

6. Yousuf S, Tali SH HIC. Clinical profile and outcome of neonates admitted to a secondarylevel neonatal intensive care unit in North India. Asian J Pharm Clin Res 2017;10(339):40.

7. Patil Ravindra B, Raghavendraswamy K SB. Clinical profile and outcome of babies admitted to neonatal Intensive care unit (NICU), Mc gann teaching hospital Shivamogga, Karnataka: A longitudinal 
study. Sch J App Med Sci 2014;2(3357):60.

8. Bhatia BD, Mathur NB, Chaturvedi P, Dubey AP. Neonatal mortality pattern in rural based medical college hospital. Indian J Pediatr [Internet] [cited 2019 Nov 26];51(410):309-12. Available from: http://www.ncbi.nlm.nih.gov/pubmed/651 1047

9. Paul VK, Jain S, Jain P, Verma M, Chacko B, Dani VS, et al. Morbidity and mortality among outborn neonates at 10 tertiary care institutions in India during the year 2000. J Trop Pediatr 2004;50(3):170-4.

10. Rakholia R, Bano M, Rawat V, Singh G. Neonatal morbidity and mortality of sick newborns admitted in a teaching hospital of Uttarakhand. CHRISMED J Heal Res 2014;1(4):228.

11. Sridhar P V, Thammanna PS, Sandeep M. Morbidity Pattern and Hospital Outcome of Neonates Admitted in a Tertiary Care Teaching Hospital, Mandya. Int J Sci c Study [Internet] 2015 [cited 2019 Nov 26];(6). Available from: www.ijss-sn.com 